\title{
Thermal Management of a Permanent Magnet Motor for an Directly Coupled Pump
}

\author{
Z. Xu, A. Al-Timimy, M. Degano, P. Giangrande, G. Lo Calzo, H. Zhang, M. Galea, \\ C. Gerada, S. Pickering, L. Xia
}

\begin{abstract}
A high speed permanent magnet motor is designed for a flooded industrial pump. Oil in the pump is used to cool the motor. Due to the limitation of space and mass requirement for the application, thermal management is one of the main challenges. This paper describes the thermal management optimization process and design of the machine. Different cooling strategies are applied to cool the machine and Computational Fluid Dynamics (CFD) is used to predict and improve the cooling performance. The machine has been designed and is currently being manufactured.
\end{abstract}

Index Terms-- Thermal management, CFD, lumped parameter, permanent magnetic, aerospace, mechanical design.

\section{INTRODUCTION}

$\mathrm{T}$ HE concept of an integrated oil pump and drive motor is widely used in various industries, mainly for the resulting benefit of requiring no shaft seals between the motor and pump. Oil in the pumping system can be used to cool the machine and the machine housing can also be used to dissipate heat for the whole pump system. An example of this can be found in various electrohydraulic actuators $[1,2]$. The motor is directly coupled to the pump and reduces the risk of mechanical jams. Also the integrated housing will reduce the overall mass of whole hydraulic system. Bidirectional rotation of the motor drives the pump to switch high pressure supply in both sides of hydraulic system directly without an extra valve manifold. This is particularly useful for a hydraulic actuator system which needs to switch direction frequently.

The thermal limit is one of the main limitations in electrical motor design [3]. When the power density of the machine is pushed to the limit to reduce the size and mass of the electrical machine, then the cooling of the machine becomes more and more important. Various cooling methods can be used to cool electrical motors and the application of the cooling strategy is dependent on the operation condition and environment of the machine. For a motor-driven pump, the most convenient way to cool the machine is to use the oil

This work was supported in part by 2013DFA70510 MoST International Cooperation.

Z. Xu ( e-mail: epzzx@nottingham.ac.uk), A. Al-Timimy ( e-mail: eexaa146@nottingham.ac.uk ), M. Degano ( e-mail: ezzmd2@nottingham. ac.uk ), P. Giangrande(e-mail: ezzpg@nottingham.ac.uk ), G. Lo Calzo (email: ezzgl1@nottingham.ac.uk ),He.Zhang (e-mail: ezahz3@nottingham .ac.uk), M. Galea (e-mail:eexmg1@nottingham.ac.uk), C. Gerada (e-mail: chris.gerada@nottingham.ac.uk) S. Pickering (e-mail: stephen.pickering (a)nottingham.ac.uk)

The authors listed above are with the Power Electronics, Machines and Control Group, the University of Nottingham, University Park, Nottingham, NG7 2RD, UK

L XIA (e-mail:fcd@facri.com), AVIC XI 'AN Flight Automatic Control Research Institute. in the pumping system. For the application described in this paper, oil is selected to remove the heat from the motor.

Computational fluid dynamics (CFD) has been well developed and applied to simulate various flow phenomena and widely in both research and industry. With a good simulation of flow field, cooling performance between fluid and solid surface where it flows over can be reliably predicted. In conjugated heat transfer with solid conduction, heat generated in the solid zones, the thermal performance of electrical machines can be predicted. [4, 5, 6]. General CFD software ANSYS Fluent [7] is used to optimize the cooling of this machine.

This paper will focus on the thermal management and mechanical design of the motor, including optimization of the cooling strategies, CFD modelling, and the cooling design of the machine.

\section{THE MACHINE}

The machine developed is an 8 pole and 9 slot surface mounted permanent magnet (SMPM) machine. Various topologies for the machine are compared. The detail of electromagnetic optimization process is not included as this is covered in another paper. The machine is rated at $10 \mathrm{Nm}$ up to $8700 \mathrm{rpm}$ and has a maximum speed of $19000 \mathrm{rpm}$ where the torque requirement is $5 \mathrm{Nm}$ (at this max. speed). The losses in different parts of the machine are listed in Table I for the two main operational speeds of 8700rpm and $19000 \mathrm{rpm}$. The worst case is at the speed of 19000rpm with a total loss of $1.45 \mathrm{~kW}$. From the table it can be seen that as for any other permanent magnet (PM) machine, the major loss is the copper loss. Therefore it is clear that the main thermal challenge is related to the windings temperature. TABLE I

THERMAL LOSSES DISTRIBUTION IN THE ELECTRICAL MOTOR

\begin{tabular}{|c|l|l|c|l|l|l|}
\hline & $\begin{array}{l}\text { Copper } \\
\text { losses }\end{array}$ & $\begin{array}{l}\text { Stator } \\
\text { Iron }\end{array}$ & Magnet & $\begin{array}{l}\text { Rotor } \\
\text { sleeve }\end{array}$ & $\begin{array}{l}\text { Rotor back } \\
\text { iron }\end{array}$ & $\begin{array}{l}\text { Total } \\
\text { losses }\end{array}$ \\
\hline $7800 \mathrm{RPM}$ & $768 \mathrm{~W}$ & $50.5 \mathrm{~W}$ & $47.5 \mathrm{~W}$ & $77 \mathrm{~W}$ & $50 \mathrm{~W}$ & $1.01 \mathrm{~kW}$ \\
\hline 19000RPM & $830 \mathrm{~W}$ & $44.4 \mathrm{~W}$ & $172.6 \mathrm{~W}$ & $257.8 \mathrm{~W}$ & $140.50 \mathrm{~W}$ & $1.45 \mathrm{~kW}$ \\
\hline
\end{tabular}

Figure 1 shows a conceptual view of the machine. The machine has an outer dimension of $80 \mathrm{mmx} 80 \mathrm{~mm}$ cross section and is about $160 \mathrm{~mm}$ in axial length. The active length of the machine is about $85 \mathrm{~mm}$. A hollow shaft is designed to reduce mass and inertia of the shaft. The PMs are attached to the rotor and constrained by an Inconel sleeve. The rotor is supported by bearings at each ends. At the drive end, a deep groove ball bearing is used. At the nondrive end, a pair of back to back bearings is used to increase the stability of rotor. Also at the non-drive end, a resolver is attached to the shaft for control of the motor. An internal 
spline coupling is designed at the drive end where the hydraulic pump is connected.

Hydraulic oil from the pump flows into motor at the front of the machine housing passes through the gap and cooling channels inside the machine and flows out at the rear end. The machine housing is designed to be oil flooded and oil tight with a maximum internal pressure of 20 bars. The maximum oil flow rate is $4.2 \mathrm{~L} / \mathrm{min}$ and the maximum oil inlet temperature is $90^{\circ} \mathrm{C}$. CFD is then applied to optimize internal oil flow paths and predict temperature distributions within the machine.

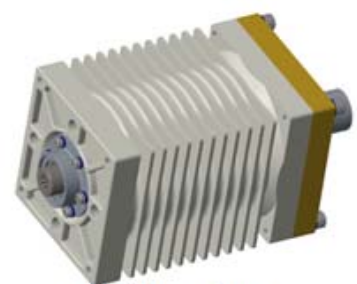

(a) Over view

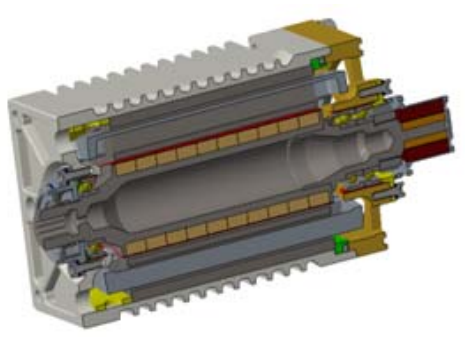

(b) Cross section view
Fig. 1. Conceptual view of the machine

As can be seen from Figure 1, a fin array is attached to the machine housing, so as to enhance the heat dissipation to air. The machine housing then serves as an additional heatsink for the whole pumping system. CFD is also applied to optimize the fin array design for the machine housing.

\section{THERMAL DESIGN OF THE MACHINE USING CFD}

\section{A. Windage losses of the machine}

The machine is cooled by hydraulic oil leaking from the compressor with a limited oil flow rate but at a high pressure. The oil flows into the machine at the front and returns to the oil reservoir at the rear of the machine. The whole rotor is immersed in oil and cooled by the oil flow through the gap. As the rotating velocity of the machine is high, the windage loss at the rotor surface becomes critical in terms of machine efficiency and machine rotor cooling. The windage losses can be estimated by the following equation (1), [8].

$$
P_{w}=\frac{1}{32} k C_{M} \pi \rho \omega^{3} D_{r}^{4} l_{r}
$$

Where $\mathrm{k}$ is the roughness of the rotor surface, $\omega$ is the angular velocity of the rotor, $\mathrm{D}_{\mathrm{r}}, \mathrm{l}_{\mathrm{r}}$, are the rotor diameter and length respectively and $\rho$ is the density of fluid, The friction coefficient $\mathrm{C}_{M}$ depends on the rotating Reynolds number defined by (2).

$$
C_{M}=A\left(\frac{2 \delta}{D_{r}}\right)^{\alpha} \mathrm{Re}^{\beta}
$$

Where the constants $A, \alpha$ and $\beta$ are related to the rotor diameter and the air-gap $\delta$.

The windage losses in air gap are also predicted using CFD by the commercial software ANSYS Fluent and compared with the above correlation. Figure 2 shows a comparison between the correlation and numerical results. A good agreement is found when the rotating speed is lower than $10 \mathrm{krpm}$, however the discrepancy increases as the rotating speed is increased. For the top speed of $20 \mathrm{krpm}$, it is clear that the correlation result is about $14 \%$ lower than that obtained by the numerical method.

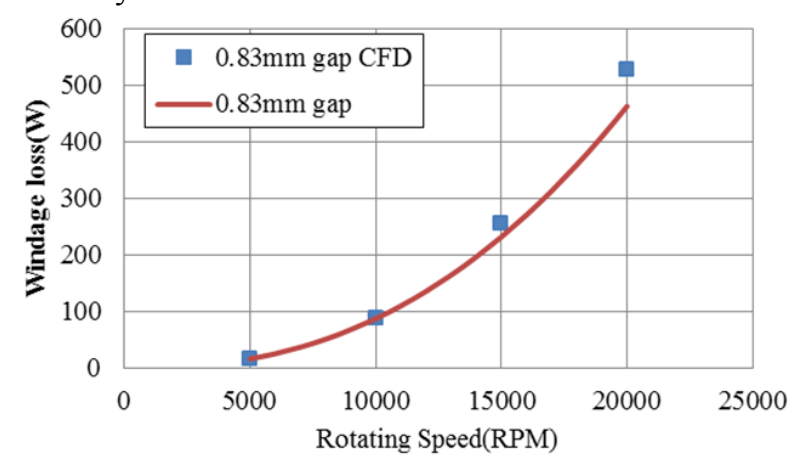

Fig. 2. Comparisons of windage losses predicted by CFD and correlation.

The above correlation is then used for further optimisation of the rotor diameter design, in order to satisfy the required electro-magnetic performance of the machine. . Fig.3 compares three different rotor diameters in terms of windage loss and speed for a fixed air gap of $0.7 \mathrm{~mm}$. This study shows that the windage losses of the rotor are increased by about $19 \%$ for a $2 \mathrm{~mm}$ increase of rotor diameter at the rotating speed of $20 \mathrm{krpm}$. In order to understand the impact of the air-gap thickness, Fig. 4 compares the losses at different speeds for four different air-gaps. It is clear that for a fixed rotor diameter of $35.8 \mathrm{~mm}$, increasing the air gap will significantly decrease the losses. For example, if a $0.2 \mathrm{~mm}$ increases of air gap thickness is implemented then a reduction of $6 \%$ to $11 \%$ of windage losses can be achieved.

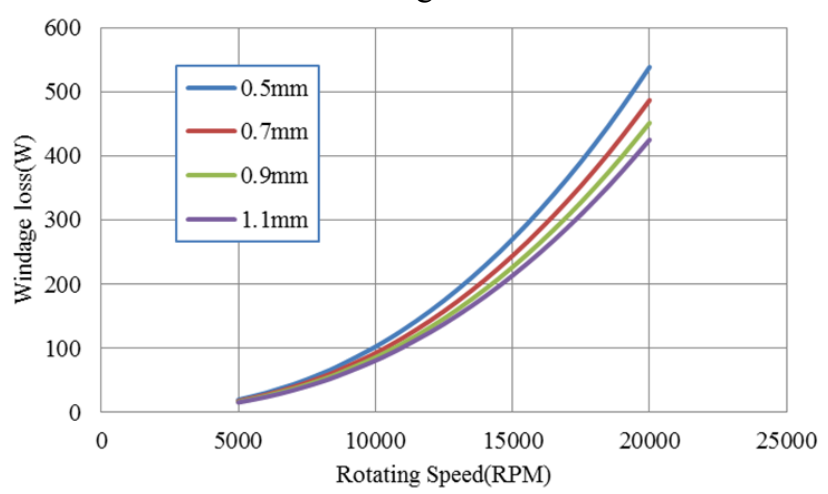

Fig. 3. Comparisons of windage losses for different rotor diameter.

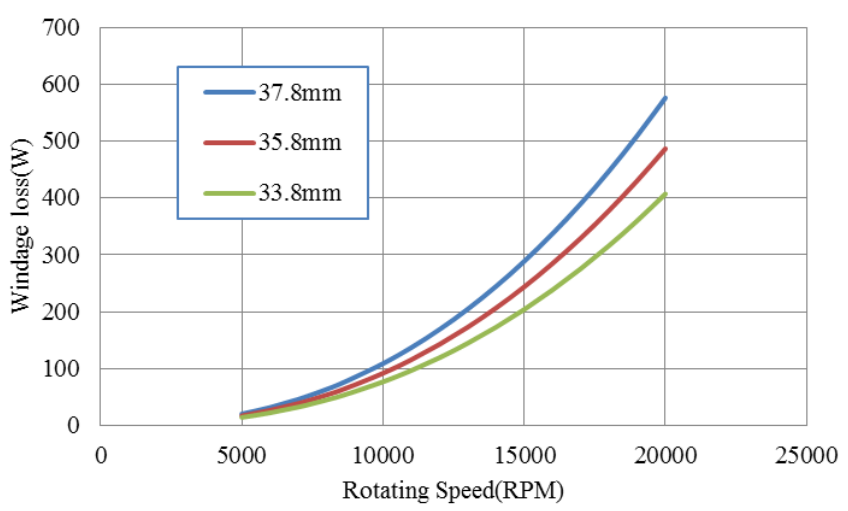

Fig. 4. Comparisons of Windage losses for different air gaps 


\section{B. CFD optimization of machine housing design}

The main heat extraction from the machine is achieved by the oil flow; however significant thermal improvement can be achieved by an appropriate design of the machine housing. Using the machine housing to also act as a heatsink then more heat can be dissipated from the whole system.

However, as no forced air is available, then only natural convection of air is present at the exterior of the machine housing. . The operating position of machine is horizontal.

Considering the above, then an investigative study to identify an optimal cooling fin arrangement was carried out. Both axial and radial fin arrays are considered for the machine housing as shown in Figure 5, with the main constraint being the maximum space envelope available. Axial fins are very often seen in motor design to help cool the machine without decreasing stiffness of machine housing. Radial fins are more applied to heat exchangers where there is a forced air flow over them.

Conjugate CFD is applied to evaluate the cooling performance of the fin design. Figure 5 shows the computational domains of 3 cases: (a) no fin, (b) an axial fin array and (c) a radial fin array. In order to save computational time, only a section of the housing is simulation with periodical boundary conditions applied to two planes in axial direction of the housing.

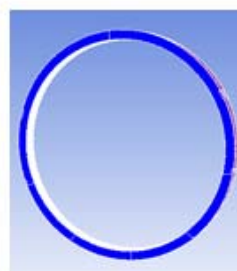

(a)

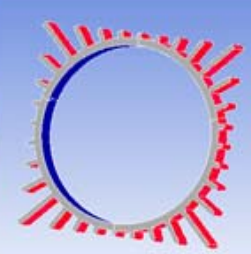

(b)

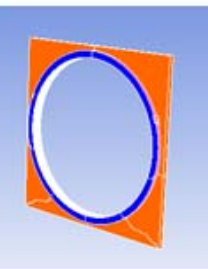

(c)
Fig. 5. Computational domains of the machine housing and fin arrays

Extensive research has been done to find heat transfer coefficients for natural convection around a heated horizontal cylinder [9], [10]. The air around the cylinder is heated up by the hot surface and flows up due to buoyancy forces generated by air density difference between hot air around cylinder and cold air in the near environment. The flow patterns and heat transfer coefficient depend on the temperature difference and the diameter of cylinder. For a given diameter horizontal cylinder, when the temperature difference is low, the flow is termed as laminar flow. Further increasing in temperature difference will increase the velocity of flow and the flow becomes turbulent. In general for a horizontal hot cylinder in air, the critical Rayleigh number when the flow becomes turbulent is $10^{8}$. The Rayleigh number for a hot cylinder is defined by (3), where $\mathrm{T}_{\text {surf }}$ and $\mathrm{T}_{\mathrm{amb}}$ are the temperatures of the hot surface and the ambient respectively, $\operatorname{Pr}$ is the Prundtl number, $\beta$ is the coefficient of thermal expansion and $v$ is the viscosity of air. $\mathrm{D}$ is the diameter of the cylinder and $\mathrm{g}$ is the gravity.

$$
R a_{D}=\frac{g \beta\left(T_{\text {surf }}-T_{a m b}\right) D^{3}}{v^{2}} \operatorname{Pr}
$$

For the machine housing with a diameter of $76 \mathrm{~mm}$, and for a temperature difference of $100^{\circ} \mathrm{C}$ between the machine and air, then the Rayleigh number is about $1.02 \times 10^{9}$ indicating that the flow around the machine housing is a turbulent flow. A turbulent model should be therefore applied when CFD is used to predict the cooling performances of different fins design. A standard $k-\varepsilon$ model with enhanced wall function [6] is applied to the simulation strategy that analyses the flow around the machine housing, in order to predict the cooling performance of different fin arrays. A uniform wall temperature is applied to the inner wall of machine housing. The same temperature and gauge pressure are applied to the pressure inlet and outlet of the flow.

Figure 6 shows the flow stream lines around the considered machine housings. For a smooth cylindrical housing, Figure 6(a), without any fins attached, air rising from the bottom flows along the surface of the cylindrical machine housing, cools the machine and is then heated by the housing. A flow separation can be seen at the top part of the cylindrical housing, where the flow becomes unstable and generates swirls and turbulence into the downstream flow. For the axial fin array case, shown in Figure 6(b), air can only reach the bottom part of the housing and flows along tips of the axial fin array. In this case, the heat generated from the machine flows in from the inner surface of the machine housing and is then transferred to the fin array and finally removed by the surrounding air. The fin array blocks direct contact between the machine housing and cold air. For a radial disk fin array case, Figure 6(c), air can flow between the gaps of radial fin array and thus, both the machine and the fin surfaces can be cooled by the flowing Better cooling performance is expected for this arrangement.

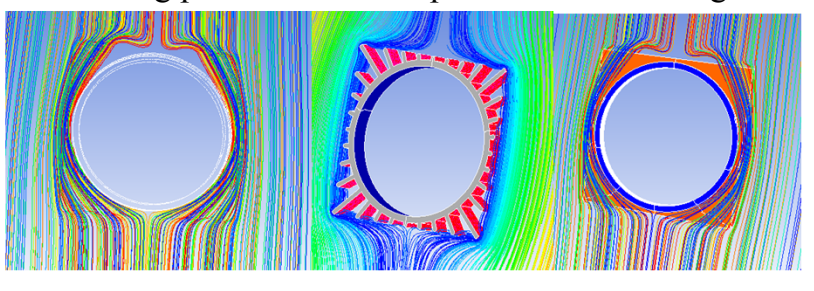

(a)

(b)

(c)

Fig 6. Flow patterns around machine for various fin arrangements

Table II compares the cooling performance of the different fin designs assuming a housing temperature of $120^{\circ} \mathrm{C}$ and an ambient air temperature of $20^{\circ} \mathrm{C}$. From Table II it can be observed that minimal improvement in terms of heat dissipation is achieved with the axial fin array design when compared to the no fin cylindrical housing. The heat dissipation per kilogram of machine housing mass is even lower than for the no fin housing. However, for a similar fin mass added to the machine housing, a radial fin array design significantly improves the overall cooling performance. The heat dissipation per kilogram (of the machine housing mass) is about 4 times higher than for the axial fin array design. All this indicates the importance of choosing a proper fin orientation, corresponding to the air flow around the surface to be cooled. Also it can be concluded that without a proper design and analysis, a fin array is not always beneficial for heat dissipation and can results in just an extra mass with no practical benefits. 
TABLE II

COOLING PERFORMANCE OF DIFFERENT MACHINE HOUSING FIN DESIGNS

\begin{tabular}{|l|c|c|c|c|c|c|}
\hline & $\begin{array}{c}\text { Fin } \\
\text { number }\end{array}$ & $\begin{array}{c}\text { Fin } \\
\text { thickness }\end{array}$ & Fin mass & Housing & Heat & $\begin{array}{c}\text { Heat } \\
\text { mass }\end{array}$ \\
\hline & & $(\mathrm{mm})$ & $(\mathrm{kg})$ & $(\mathrm{kg})$ & $(\mathrm{W})$ & $(\mathrm{W} / \mathrm{kg})$ \\
\hline No fin & 0 & 0 & 0 & 0.16 & 42.60 & 269.78 \\
\hline Axial fin & 17 & 2 & 0.18 & 0.34 & 56.14 & 167.12 \\
\hline Radial fin & 17 & 2 & 0.17 & 0.33 & 238.34 & 724.48 \\
\hline
\end{tabular}

\section{CFD Optimization stator cooling}

As the machine stator is directly cooled by hydraulic oil from the pump system, then this allows for 'much higher than typical' current densities to be used. For the application at hand, a current density $\mathrm{J}$ of $27 \mathrm{~A} / \mathrm{mm}^{2}$ was used. However this indicates that considerable copper losses are generated. In fact more than $1 \mathrm{~kW}$ of copper losses are generated in the coil and this needs to be removed from the slots of the stator laminations. Different cooling strategies are thus considered including traditional oil jackets and localized cooling channels at various locations in the stator. It is found that cooling channels within the coil slots is the most efficient way to remove copper losses from coil. Figure 7 shows the different cooling channel concepts explored in order to get the best stator cooling possible.

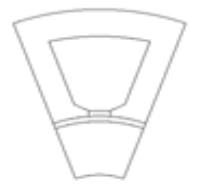

(a)

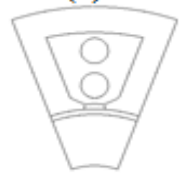

(c)

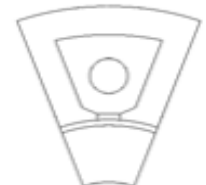

(b)

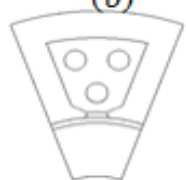

(d)
Fig 7. Various cooling options for the machine, (a) air gap only; (b) air gap and 1 cooling channel; (c) air gap and two cooling channels; (d) air gap and 3 cooling channels

TABLE III

VARIOUS COOLING CHANNELS WITHIN THE COIL OF STATOR

\begin{tabular}{|l|c|c|c|c|c|}
\hline & $\begin{array}{l}\text { Cooling } \\
\text { channels }\end{array}$ & $\begin{array}{c}\text { Cross area } \\
\left(\mathrm{mm}^{2}\right)\end{array}$ & $\begin{array}{c}\text { Total area } \\
\left(\mathrm{mm}^{2}\right)\end{array}$ & Gap & Channel \\
\hline Case a & 0 & 10.6 & 10.6 & $100 \%$ & 0 \\
\hline Case b & $1 \mathrm{x} \varnothing 5 \mathrm{~mm}$ & 19.6 & 30.2 & $35 \%$ & $65 \%$ \\
\hline Case c & $2 \mathrm{X} \varnothing 4 \mathrm{~mm}$ & 25.1 & 35.7 & $30 \%$ & $70 \%$ \\
\hline Case d & $3 \times \varnothing 3 \mathrm{~mm}$ & 21.2 & 31.8 & $33 \%$ & $67 \%$ \\
\hline
\end{tabular}

As the machine is flooded with oil and operated at $20 \mathrm{krpm}$, high windage losses are expected at the rotor surface. The thermal management of the rotor is thus also very important, especially when considering the presence of PMs in the rotor. For a fixed oil flow rate, the oil quantities used to cool both stator and rotor need to be optimized. Table III shows the cross-sectional areas of the considered cooling channels, shown in Figure 7. An important aspect with these designs is that higher flows are required in the stator cooling channels than in the machine air-gap.
Computational Fluid Dynamics (CFD) is used to model the cooling performance of the different oil flow paths... Figure 8 presents the computational domains of the 4 cases, where only a $1 / 9$ section of machine, is simulated comprising only 1 slot. The stator laminations and the rotor are also included in order to increase the accuracy of the model. The same mass flow rates for all four cases are for a number of different cooling paths. Periodic boundary conditions are then applied to the two sides of the cylindrical surfaces. Conjugate CFD is used to predict the flow and cooling performances for both stationary and rotating parts.
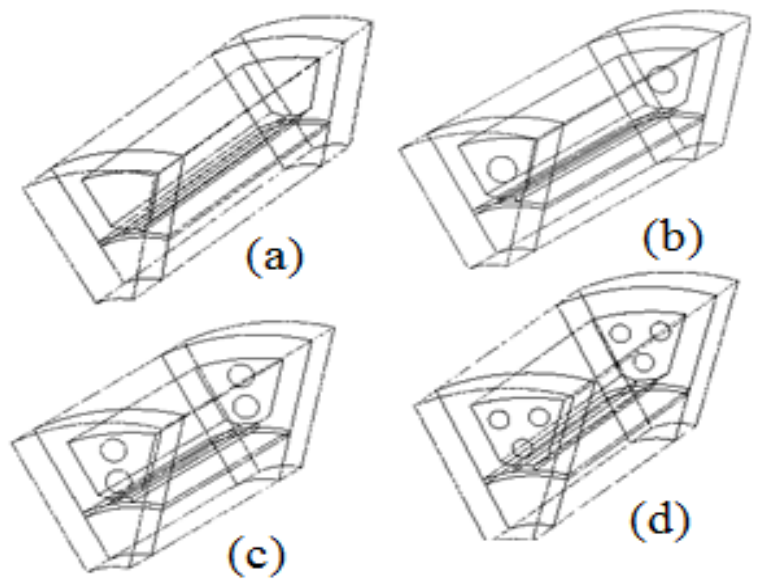

Fig 8. CFD computational domains of machine cooling paths, (a) air gap only; (b) air gap and 1 cooling channel; (c) air gap and two cooling channels; (d) air gap and 3 cooling channels

Figure 9 shows the velocity vector distributions of flow in the air gap and cooling channels for the different cooling options at stationary cases. In case (a), all oil flows through the air gap with a relative high speed. In cases (b) to (d), we can see the oil flow through both air gap and channels in the slots and cool the coil directly. Knowing the flow distributions for the stationary cases, then the effects of the rotating flow can be found by comparing the flow distributions for the same inlet and outlet conditions.
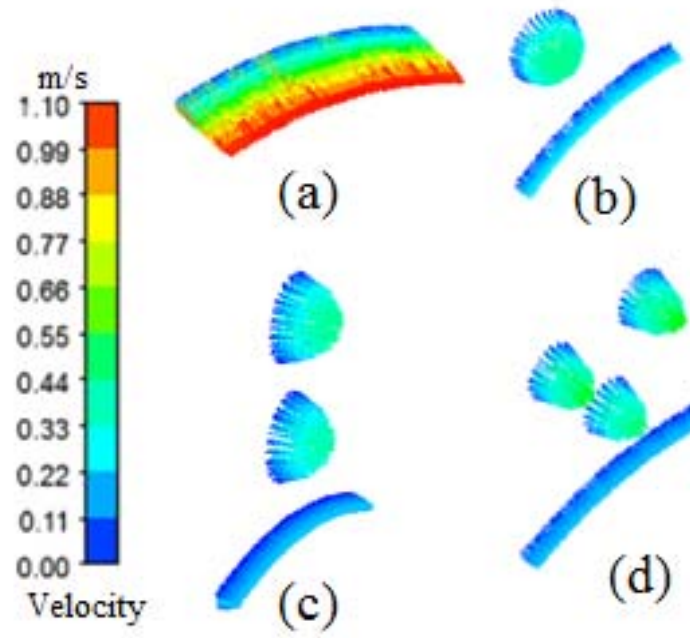

(b)

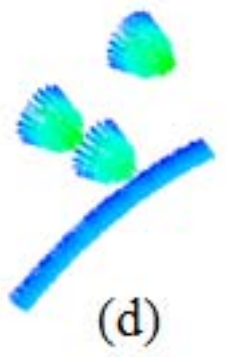

Fig 9. Velocity vectors in oil gap and cooling channels for stationary cases, (a) air gap only; (b) air gap and 1 cooling channel; (c) air gap and two cooling channels; (d) air gap and 3 cooling channels 
Table IV lists the oil flow distributions in terms of percentages of the total oil flow rate. For the case of no cooling channels in the slots, all the oil flows through the oil gap. The maximum velocity in the oil gap is about $1.1 \mathrm{~m} / \mathrm{s}$. For case b, one cooling channel of $5 \mathrm{~mm}$ diameter is designed in the center of slot, thus $76 \%$ of the oil flows through the cooling channel and successfully removes heat from the machine coil. For case c, with 2 channels of $4 \mathrm{~mm}$ diameter, $19 \%$ of the oil flows through the machine air-gap and the rest of the oil flows through the cooling channels. For case d, 3 cooling channels of $3 \mathrm{~mm}$ diameter are equally distributed in the slot. In this case, the flow rate of the two cooling channels closer to the stator yoke, is slightly higher than that of the one closer to the air-gap.

$$
\text { TABLE IV }
$$

OIL FLOW RATE DISTRIBUTION AT OIL GAP AND COOING CHANNELS

\begin{tabular}{|c|c|c|c|c|}
\hline & Oil gap & Channel 1 & Channel 2 & Channel 3 \\
\hline Case a & $100 \%$ & & & \\
\hline Case b & $18 \%$ & $82 \%$ & & \\
\hline Case c & $15 \%$ & $40 \%$ & $45 \%$ & \\
\hline Case d & $15 \%$ & $26 \%$ & $30 \%$ & $29 \%$ \\
\hline
\end{tabular}

Figure 10 shows the contours of the axial oil velocities in the air-gap and the cooling channels for the different cooling options, with the rotor rotating at $20 \mathrm{krpm}$. The detailed oil flow rate distributions in different channels are listed in Table V. Comparing the oil flow rate distributions for the stationary and rotating cases, it is clear that the cooling oil is slightly pushed outwards to the cooling channels and the oil flow through the oil gap is slightly reduced. The high speed rotation generates a flow resistance in the air-gap and results in lower flow rate in the oil gap.

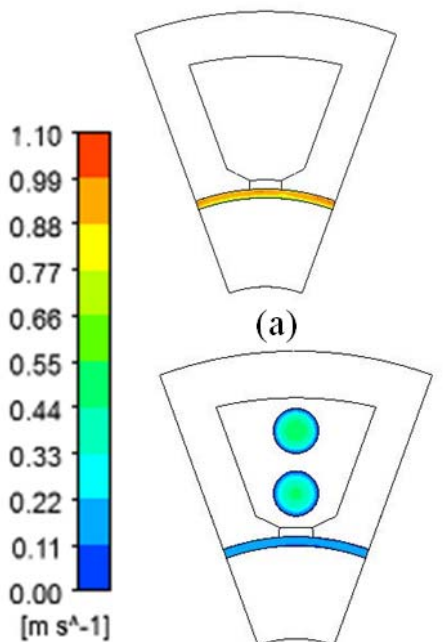

(c)

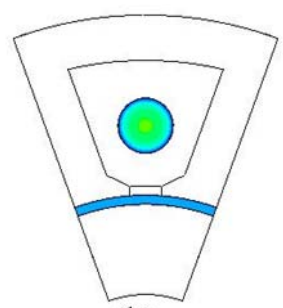

(b)

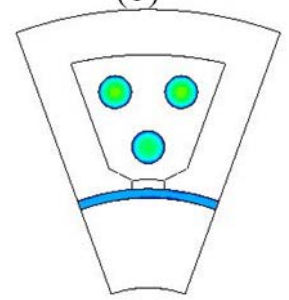

(d)
Fig 10. Contours of axial velocity for various cases at $20 \mathrm{krpm}$

To compare the cooling performance of the cooling options, a heat loss of $1200 \mathrm{~W}$ is applied to the coils and a total loss of 792W (representing the windage loss and any eddy current loss in the PMs and metal sleeve) are applied to the four models. An iron loss of $72 \mathrm{~W}$ is applied to the stator laminations. A slot-liner material ( $0.5 \mathrm{~mm}$ Nomex 410 paper) is also added to represent the insulation between the coils and the slot walls.

TABLE V

OIL FLOW RATE DISTRIBUTION AT OIL GAP AND COOING CHANNELS 20KRPM

\begin{tabular}{|c|c|c|c|c|}
\hline & Oil gap & Channel 1 & Channel 2 & Channel 3 \\
\hline Case a & $100 \%$ & & & \\
\hline Case b & $24 \%$ & $76 \%$ & & \\
\hline Case c & $19 \%$ & $38 \%$ & $43 \%$ & \\
\hline Case d & $19 \%$ & $25 \%$ & $28 \%$ & $28 \%$ \\
\hline
\end{tabular}

Figure 11 shows the cooling performance of the four cooling options for a stationary rotor. Oil temperature rising is predicted by CFD, but the effects of temperature rising of oil on thermal properties are not included in the CFD. The effects are limited as the temperature rising is very low. As shown in Fig. 11, oil flow through the gap is not enough to achieved satisfactory cooling of the coils However the inclusion of cooling channels in the slot result in a significant reduction of the coil temperature. The more cooling channels embed in the slot, the better cooling performance is obtained. It is clear that option d) can reduce the temperature of the coils by more than $50 \%$.

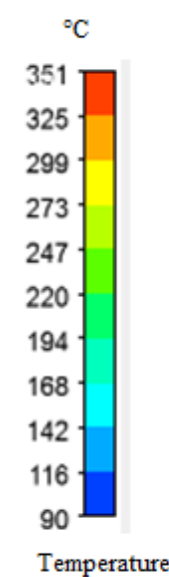

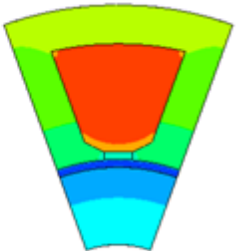

(a)

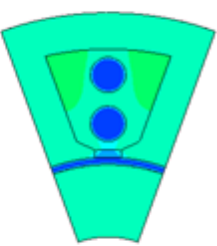

(c)

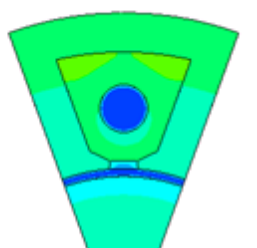

(b)

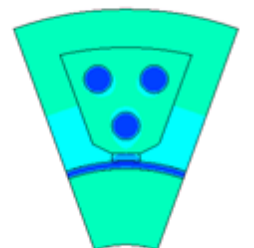

(d)
Fig 11. Temperature contours of various case cases at stationary condition

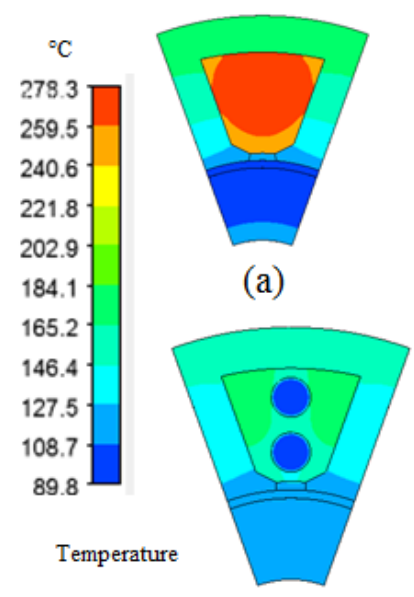

(c)

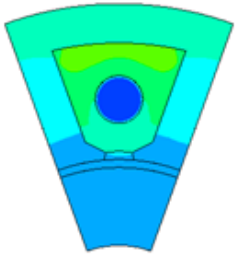

(b)

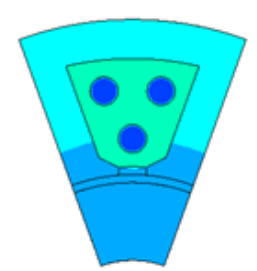

(d)
Fig 12. Temperature contour of various cases at $20 \mathrm{krpm}$ 
Figure 12 shows the cooling performance of the different cooling channels at $20 \mathrm{krpm}$ Figure 13 shows the $3 \mathrm{D}$ temperature contours of the machine for the same conditions as those shown in Figure 12. By comparing with the stationary cases shown in Figure 11, it is clear that the coil temperatures (for all cooling cases) are significantly reduced. Cooling performance in the air gaps is improved due to high rotating speed of the rotor generated high speed velocity flow near both side surfaces of air gap. Table VI lists the maximum temperatures of the coil, the stator and the rotor of the machine for the four cases at the high speed operational point. Although the rotating fluid in the gap does improve the cooling performance at the surfaces of the stator, however without any slot cooling channels the temperatures in the coils would be too high. Comparing cases $\mathrm{b}$ and $\mathrm{c}$ with case a, the maximum temperature in the coil is significantly reduced. Cooling channels in the slots are therefore critical to reduce temperatures in stator coils. There is no significant difference in coil temperature between case b and case $c$. From all the above, it can be concluded that the optimal cooling option for the application at hand is the one with 3 cooling channels.

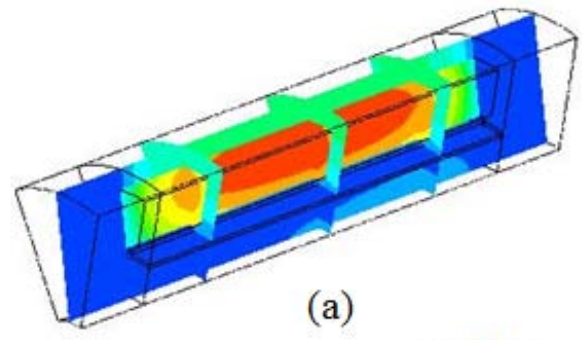

(a)

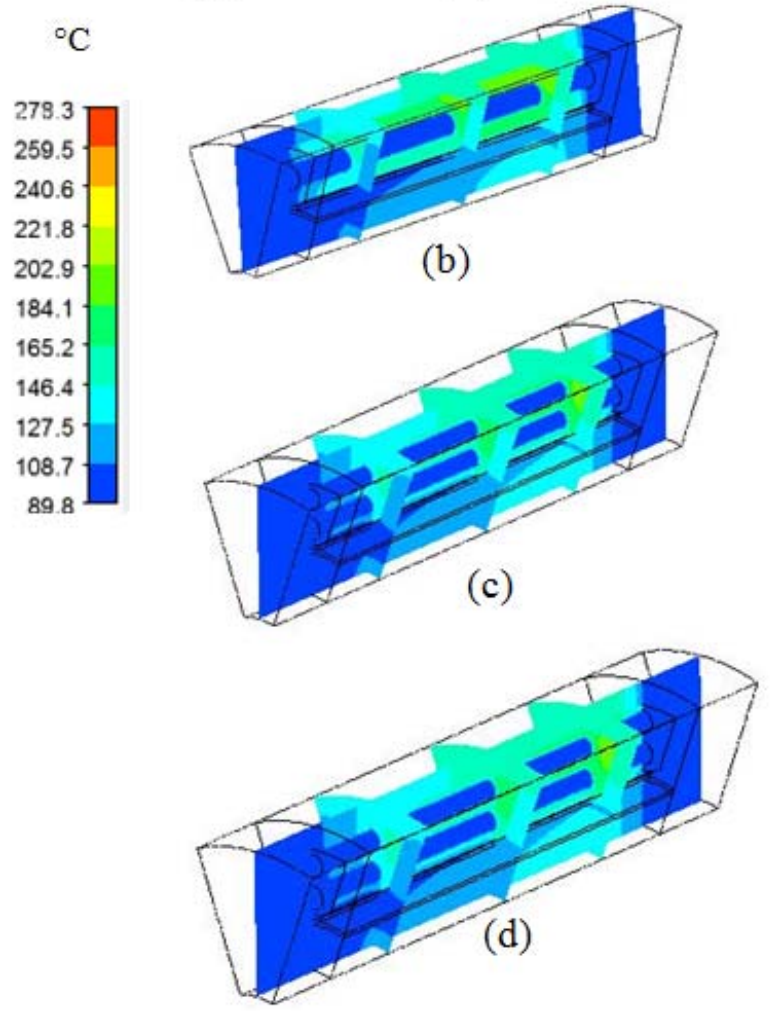

Fig 13. 3-D temperature contour of various cooling cases at $20 \mathrm{krpm}$
Also from table VI, it can be seen that for when no cooling channels are implemented in the slot, a better cooling is obtained from the rotor perspective. This is due to all the cooling oil being forced into the machine air-gap. . If the loss in the rotor is considerably high and more cooling effort is needed, then adding more cooling channels in the slot will not be beneficial from the total machine performance perspective. It is also clear that the loss distribution of the particular application will define the appropriate cooling method and the optimal cooling path design.

From the CFD studies of the cooling performances of the machine, it was found that creating cooling channels inside the slot is essential to cool the machine. In order to verify the feasibility of creating the proposed channels a dummy stator was manufactured using 3D rapid prototyping technology. Figure 14 shows pictures of the dummy stator with the actual machine coils, wound and inserted. . This confrims that the proposed channels can actually be manufactured. In fact Fig. 14(a) shows the option with one large channel of $\varnothing 5 \mathrm{~mm}$ in the middle of slot and Fig. 14(b) shows the same slot but with three small channels for flow of oil.

TABLE VI

COOLING PERFORMANCES OF 4 CASES AT 20KRPM

\begin{tabular}{|l|c|c|c|}
\hline & T Coil max $\left({ }^{\circ} \mathrm{C}\right)$ & T rotor max $\left({ }^{\circ} \mathrm{C}\right)$ & $\mathrm{T}$ lam $\max \left({ }^{\circ} \mathrm{C}\right)$ \\
\hline Case a & 278.4 & 112.3 & 180.9 \\
\hline Case b & 195.0 & 134.4 & 161.8 \\
\hline Case c & 191.0 & 136.6 & 162.3 \\
\hline Case d & 170.8 & 137.0 & 154.9 \\
\hline
\end{tabular}

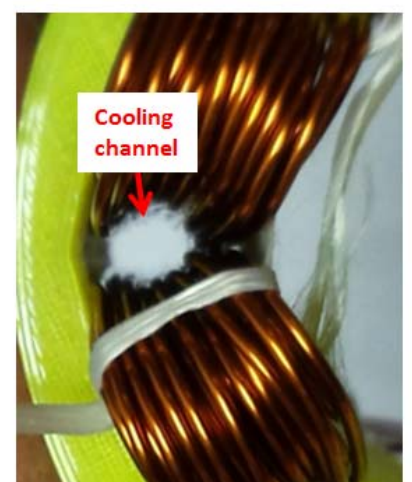

(a) One cooling channel

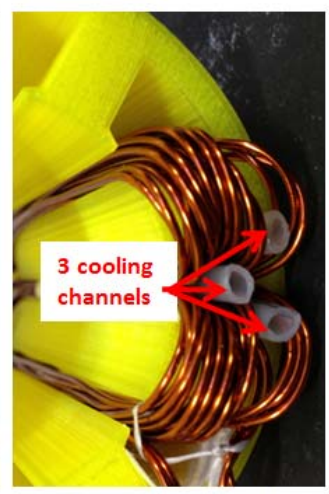

(b) 3 cooling channels
Fig 14. Cooling channels in a slot of a dummy stator

\section{CONCLUSIONS}

Conjugate Computational Fluid Dynamics (CFD) is applied to the thermal design of a small, high performance motor directly cooled by oil. A high windage loss is expected due to the machine rotating at relatively high speeds with the rotor completely immersed in oil. . The built CFD models predicted the windage loss and agreed very well with the analytical models.

In this paper, CFD is also used for the identification and design of an optimal fin arrangement of the machine housing, where he CFD result demonstrates that the optimal fin array orientation depends on the machine operation position. For a horizontal machine, a disk fin array is about four times better (in terms of heat dissipation) than an axial 
fin array for the same envelope dimension of the machine housing.

The internal oil-flow inside the machine is also predicted using CFD. It is found that implementing a cooling channel within the stator slot is critical to cool the machine. A study of the optimal configuration of these slot channels was done and presented, where it was concluded that having several channels evenly distributed in the slot, can provide a better cooling performance for the machine windings. . Flow rate distributions in the machine are predicted for various cooling channel options for both stationary and rotating conditions. It is found that the flow is pushed outwards by rotation but, the effect of rotation on flow distribution is limited and can be negligible.

In order to prove the feasibility of the proposed cooling arrangements, a dummy stator was manufactured using 3D printing technology. For the application at hand with the actual machine windings inserted into this dummy stator, the option of creating cooling channels was proven. The machine described in this paper is currently being manufactured and experimental tests to validate the concepts described here will be performed in the near future.

\section{REFERENCE}

[1] Chris Gerada, and Keith J. Bradley, WheelTug, "WheelTug Tests December, 2010", IEEE TRANSACTIONS ON INDUSTRIAL ELECTRONICS, vol 55, NO. 9, SEPTEMBER 2008,

[2] Jean-Claude Derrien, Sagem Défense Sécurité, "Electromechanical actuator (EMA) advanced technologies for flight controls", $28 T H$ INTERNATIONAL CONGRESS OF THE AERONAUTICAL SCIENCES

[3] M. Galea, C. Gerada, T. Raminosoa, and P. Wheeler, "A Thermal Improvement Technique for the Phase Windings of Electrical Machines," IEEE Transactions on Industry Applications, vol. 48, pp. 79-87, 2012.

[4] Z. Xu, A. La Rocca, S. J. Pickering, C. Eastwick, C. Gerada, S. Bozhko, "Mechanical and Thermal Design of an Aeroengine Starter/Generator", IEEE, international electrical machine and drive conference(IEMDC), Coeur d'Alène, Idaho USA, 2015

[5] Z. Xu, M. Galea, C. Tighe, T. Hamiti, C. Gerada, S.J. Pickering, "Mechanical and thermal management design of a motor for an aircraft wheel actuator", IEEE, the 17th International Conference on Electrical Machines and Systems (ICEMS2014), Hangzhou, China, Oct, 2014,

[6] Connor, P.H., et al. "CFD modelling of an entire synchronous generator for improved thermal management. in Power Electronics, Machines and Drives" (PEMD 2012), 6th IET International Conference on. 2012.

[7] http://www.ansys.com/Products/Fluids/ANSYS-Fluent

[8] Pyrhonen, J., T. Jokinen, V. Hrabovova, "Design of rotating electrical machines", 2008, Chichester, West Sussex, UK, Wiley.

[9] K. Kitamura, F. Kami-iwa, T. Misumi, "Heat transfer and fluid flow of natural convection around large horizontal cylinders", International Journal of Heat and Mass Transfer vol. 42 (1999) pp. 4093-4106

[10] S.K.S. Boetcher, "Natural Convection from Circular Cylinders", Springer Briefs in Thermal Engineering and Applied Science, DOI: 10.1007/978-3-319-08132-8_2

\section{BIOGRAPHIES}

Zeyuan Xu obtained his $\mathrm{PhD}$ in in mechanical engineering from the University of Manchester, England, in 2002. He subsequently worked as a researcher at UMIST, Brunel University and University of Nottingham. His main research interests are in turbulent thermofluid flow, heat transfer enhancement, thermal management of advance electrical motor and power electronics, and mechanical design of high speed electrical machine.
Ahmed Al-Timimy received his M.Sc. degree in Electrical Engineering from the University of Technology, Baghdad, Iraq in 2012. He is currently working towards his PhD in electro-magnetic and electrical machine design with Power Electronics, Machines and Control Group at the University of Nottingham. His main research interests are design and analysis of high performance electrical machines for aerospace applications.

Michele Degano received the Laurea degree in electrical engineering from the University of Trieste, Trieste, Italy, in 2011 and the Ph.D. degree in industrial engineering from the University of Padova, Padova, Italy, in 2015. He is currently a Research Fellow with the Power Electronics, Machines and Control Research Group, The University of Nottingham, Nottingham, U.K. His main research interests are in the design and optimization of permanentmagnet machines and reluctance and permanent magnet-assisted synchronous reluctance motors through genetic optimization techniques, in applications ranging from small to large power.

Paolo Giangrande was born in Monopoli, Italy, in March 1982. He received the Ph.D. degree in electrical engineering from the Technical University of Bari, Bari, Italy, in 2011. In 2008, he was a Marie Curie IntraEuropean Fellow at the University of Malta, Tal-Qroqq, Malta. Since January 2012, he has been a Research Associate with the PEMC Group, The University of Nottingham, Nottingham, U.K. His research interests include sensorless control of ac electric drives and intelligent motion control, as well as design, modeling, and parameter identification of electrical machines for aerospace applications.

Giovanni Lo Calzo received the Master's degree and the $\mathrm{PhD}$ degree from the University of ROMA TRE, Rome, Italy, respectively in 2010 and 2015.From 2010 to 2011, he was a Research Assistant with the University of Roma Tre. He is currently a Research Fellow with The University of Nottingham, Nottingham, UK, in the Power Electronics, Machine and Control Group. His research interests are mainly focused on power electronics converters for high speed machines, control and modelling of grid-tied and isolated inverters, output filter topologies.

Michael Galea received his PhD in electrical machines design from the University of Nottingham, UK, where he has also worked as a Research Fellow. He is currently a Lecturer in Electrical Machines and Drives within the PEMC research group of the University of Nottingham. He is the Deputy Director of the Institute for Aerospace Technology at the University of Nottingham, where he is also a Lecturer in Aerospace Systems Integration. His main research interests are design, analysis and thermal management of electrical machines and drives.

Chris Gerada obtained his $\mathrm{PhD}$ in Numerical Modelling of Electrical Machines from the University of Nottingham, UK in 2005. He subsequently worked as a researcher at the University of Nottingham on high performance electrical drives and on the design and modelling of electromagnetic actuators for aerospace applications. He was appointed as Lecturer in Electrical Machines in 2008, an Associate Professor in 2011 and Professor in 2013. His core research interests include the design and modelling of high performance electric drives and machines. Prof. Gerada holds a Royal Academy of Engineering / Cummins Chair in Electrical Machines. He is also an Associate Editor for the Transactions in Industry Applications and is the Chair of the IEEE Industrial Electronics society electrical machines technical committee.

He Zhang received his B.Eng. degree from Zhejiang University, China, in 2002. He obtained the Ph.D. degree in electrical machines from The University of Nottingham, UK, in 2009. Then he joined the UK Water Research Centre, and worked on energy efficiency determination for motor drive system for two years. He is currently a Senior Research Fellow and Director of Best motion machine drive technology center within the Power electronics, Machines and Control research group in University Of Nottingham. His research interests include high performance electric machines and drives.

Steve Pickering received the B.Sc. and Ph.D. degrees in mechanical engineering from the University of Nottingham, Nottingham, U.K., in 1979 and 1984, respectively. Since 1988, he has been a Lecturer with the University of Nottingham, where he is currently a Hives Professor and Reader in the Faculty of Engineering. He has extensive research experience in Thermofluids and has undertaken research into the cooling of electric machines for over ten years.

Liqun Xia graduated from the Beijing institute of technology, China, in 1990. He then joined AVIC FACRI in 1990 and received his PhD degree from the Northwestern Polytechnical University, China in 2010. He is currently a chief engineer in actuation systems. His research interest is in servo system design and simulation, actuator design and modelling and system control loop strategies 